\title{
The specialist nursing workforce caring for men with prostate cancer in the UK
}

\author{
Alison Leary, Jane Brocksom, Ruth Endacott, Louisa Fleure, Felicity Howdle, \\ Morven Masterton, Anita O'Connor, Adrian Swift, Paul Trevatt and Philippa Aslet
}

\begin{abstract}
Prostate cancer is the most common cancer in men in the UK accounting for $25 \%$ of all new cases of cancer. It is predicted to become the most common cancer overall by 2030. A national survey of the specialist nursing workforce caring for men with prostate cancer was completed across the four countries of the UK during June and July 2014. In total 302 specialist nurses completed the survey and data from 285 was used in the analysis. This is the biggest whole population survey of this workforce in recent years. The most common job title was clinical nurse specialist (185) and the most common band was agenda for change band 7 (174). However in Scotland $50 \%$ of the respondents stated that they were paid on band 6. Over half the group (158) had worked in prostate cancer care for more than 10 years. Few (48) had come into specialist posts from a specific specialist nurse development role. There is wide geographic variation in the provision of specialist nursing for men with prostate cancer. This is reflected in available hours and caseload sizes. The respondents reported frozen and vacant posts across the UK. This equated to 58.3 full time equivalents. The work of specialist nurses caring for men with prostate cancer is clinically complex and appears to cover most key times in the cancer journey. However workload appears to be limiting the care that the nurses are able to provide with over half the respondents (163) saying that they left work undone for patients.
\end{abstract}

Key words: Clinical nurse specialist • Nursing cancer • Prostate cancer • Workforce

\section{RATIONALE/BACKGROUND FOR THE STUDY}

Prostate cancer is the most common cancer in men in the UK accounting for $25 \%$ of all new cases of cancer and it is predicted to become the most common cancer

Authors: A Leary, PhD, RN, Professor of Healthcare \& Workforce Modelling, London South Bank University, London, UK; J Brocksom, EN, RGN, BHSC, Hons, Urology/Continence Nurse Specialist, St James's University Hospital, Leeds, UK; R Endacott, RN, DipN(Lond), CertEd, MA, PhD, Director, Centre for Health and Social Care Innovation, Plymouth University, Plymouth, UK; L Fleure, BSc, (Hons), PGDip, MSc, RN, Prostate Cancer Advanced Nurse Practitioner, Guy's and St Thomas' NHS

Foundation Trust, London, UK; F Howdle, Senior Information Analyst, Mouchel Management Consulting Limited and, Centre for Workforce Intelligence, London, UK; M Masterton, BA, (Hons), MA, Health Professionals Engagement Manager, Prostate Cancer UK, London, UK; A O'Connor, BSc, (Hons), MSc, Research Assistant, Centre for Health and Social Care Innovation, Plymouth University, Plymouth, UK; A Swift, Mouchel Management Consulting Limited and Centre for Workforce Intelligence, London, UK; P Trevatt, MSc, RGN, Strategic Clinical Network Lead, CVD/EOL, London Region, NHS England, London, UK; P Aslett, BA, (Hons), RGN, BAUN President 2012-2014

Address for correspondence: Professor of Healthcare \& Workforce Modelling, London South Bank University, London, UK

E-mail: alisonleary@yahoo.com overall by 2030 (Mistry et al., 2011). Over 41000 men were diagnosed with prostate cancer (114/d) in the UK in 2011 and over a quarter of a million men are living with and after prostate cancer (Maddams et al., 2014). Over the last 40 years prostate cancer incidence rates in Great Britain have more than tripled (Cancer Research UK, 2014a). Almost three-quarters (74\%) of prostate cancer cases are diagnosed in men aged 65 years and older (Cancer Research UK, 2014b) and it is the second most common cause of cancer death in men, after lung cancer, causing over 10,000 deaths in the UK in 2012 (Cancer Research UK, 2014c). The National Cancer Patient Experience Survey (NCPES) in England has showed that patients with cancer who have access to a clinical nurse specialist (CNS), generally report better experiences and understanding of the disease (Department of Health, 2010, 2012; NHS England, 2013, 2014).

Recent empirical and anecdotal evidence has highlighted issues about the current urology nursing workforce and its ability to meet the future needs of the increasing number of men suffering from prostate cancer and prostate disease. Specialist cancer nursing is widely recognized as an essential part of cancer 
care, providing technical expertise, meeting information needs and offering emotional support and coordination (Department of Health, 2007). Clinical nurse specialists (CNSs) play a key role in the prostate cancer patient pathway but there is concern that specialist nursing provision is insufficient, inconsistent and inequitable (Trevatt and Leary, 2010), and will be unable to meet increasing demand for specialist cancer nursing care across the UK. In addition there are few opportunities for progression or systems leadership with only three uro-oncology consultant nurse posts currently in England (Macmillan Cancer Support, 2014). These workforce challenges must be seen in the wider context of NHS reforms, in particular with respect to tightened budgets and a move to provide more care in the community/primary care settings, rather than in secondary care.

Specialist nurse roles have been an informal part of the cancer nursing workforce for many years, with the first formal recognition provided in the Calman-Hine report (Department of Health, 1995). A number of drivers have influenced the number and extent of CNS role development over the past two decades including reduced availability of junior doctors, the EU working time directive and the introduction of waiting time targets (Department of Health, 1999, 2000). However, in contrast to these reactive drivers for role development, cancer nursing was identified as a key component of the English NHS Cancer Plan in 2000. A decade on, the role of the CNS in oncology was reported as ill-defined, with a wide variation in job titles, responsibilities, training and expected competencies (Farrell et al., 2011); findings from a study conducted across four NHS Trusts in the UK with uro-oncology nurses working in prostate cancer showed similar wide variation in qualifications, experience and services provided (Ream et al., 2009). This is not unique to the UK, with similar problems articulated in Australia (Lowe et al., 2012).

Within cancer policy, the value and significance of the post appears to have grown exponentially, from limited referencing in early policy documents $(\mathrm{DH}, 1995$, 2000) to more detailed recommendations clearly articulating the role, value and worth, together with challenges variability and access to CNS services. Later cancer policy $(\mathrm{DH}, 2007,2011)$ set out clear messages to providers and commissioners about provision and CNS numbers. These documents were further complimented by national reports which defined the economic value of the specialist role in terms of quality improvement, increased productivity and efficiency (NCAT, 2010, 2011).

The value and importance of the role was further articulated in the findings of the English NCPES (DH, 2010, 2012; NHS England, 2013, 2014), which demonstrated a clear relationship between positive patient experience and CNS access.

The latest evidence suggests that patient contact with a cancer CNS has increased from 84\% (Department of Health, 2010) to 89\% (NHS England, 2014).

Not all men with prostate cancer are receiving access to a named specialist nurse. Findings from the NCPES in England in 2014 identified that $88 \%$ of the 6288 prostate cancer respondents had been given the name of a CNS who would be in charge of their care, with the poorest trust reporting only 32\% (NHS England, 2014). According to the National Prostate Cancer Audit, almost all (95\%) of the 142 NHS trusts in England provide access to a urological CNS and 67 (47\%) provide access to an oncological CNS. The National Cancer Director in England reported that the care provided by nurse specialists was 'one of the most positive aspects of the survey' (Richards, 2010). The Welsh Cancer Patient Experience Survey reported that 54\% of men in Wales with prostate cancer were given the name and contact details of their key worker (Welsh Government, 2014). In Scotland, 76\% of prostate cancer patients were given the name of a specialist nurse (Prostate Cancer UK, 2013). Taken as a whole, these challenges point to the need to map uro-oncology CNS roles, in order to inform future workforce planning.

\section{RESEARCH QUESTIONS OR AIMS OF PROJECT}

The aim of this project was to gain an understanding of the current nursing workforce providing care for men with prostate cancer across all four countries of the UK. This included demographic information and areas of need such as education and development and workload.

\section{Sample}

This is a whole population sample study. The available population was determined by the British Association of Urological Nurses (BAUN) membership and the previous national census (Macmillan Cancer Support, 2014).

\section{Data collection methods}

A 24-item survey questionnaire was developed for this population by consensus using clinical and academic experts. This was transferred to an online survey tool (Survey Monkey secure account). Ethical approval was sought and granted by Plymouth University ethics committee. The survey was developed during April and May 2014 and distributed through formal and informal networks, mailing lists, the nursing press, targeted interest groups such as BAUN, NHS Contact, 


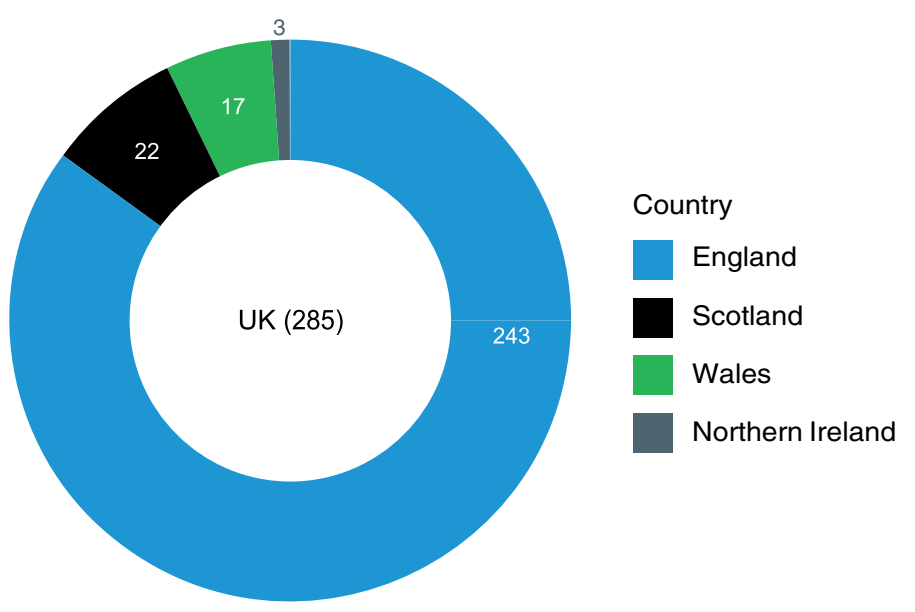

Figure 1 Response by country.

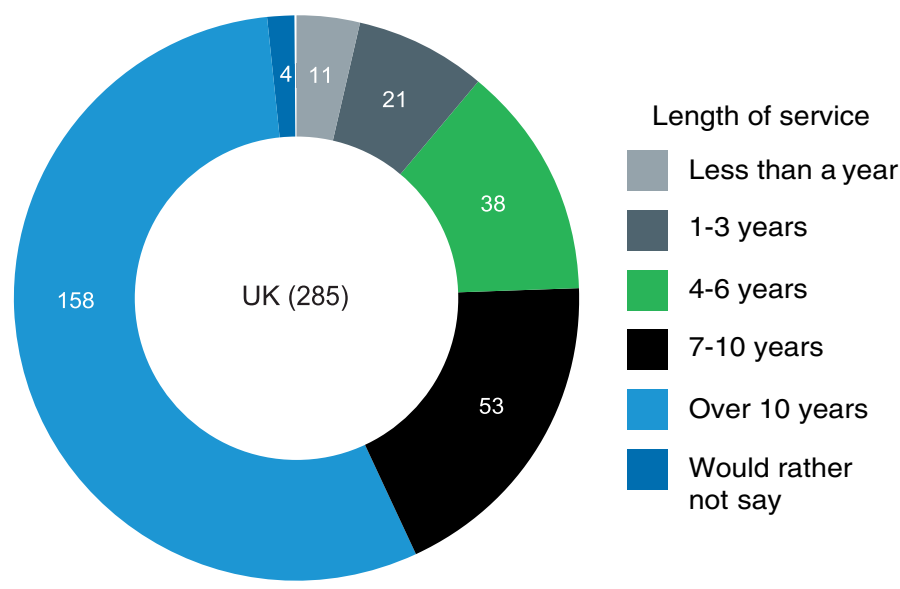

Figure 2 Workforce by length of service.

Help, Advice and Information Network (CHAIN), the UK Oncology Nursing Society (UKONS) and social media (Twitter) during June and July of 2014.

\section{Data analysis}

Data was exported into Excel and modelled using a descriptive statistics approach. Participants in the survey were also invited to provide additional information on areas such as education, workload or any other issues they felt relevant. These free text comments were analysed using thematic content analysis. Each comment was coded and themes emerged from the codes. Data excerpts are included below alongside quantitative findings, to provide context. Excerpts are annotated according to job title and pay band (e.g. CNS/band 6).

\section{Findings/Results}

There were 302 respondents in total. After cleaning, the data from 285 respondents was used. The other records were removed as they were incomplete submissions or submissions from countries outside of the UK. Data was collected from across the UK however it should be noted that the four countries of the UK have different cancer policies and systems to deliver cancer care. In addition, the size of the workforce varies significantly; this is reflected in the number of responses from each country. Wales and Northern Ireland had the lowest number of responses (Figure 1). According to the survey results, the number of nurses providing specialist care to men with prostate cancer across the UK is shown in Figure 1.

\section{Demographics}

The majority of the group is at band $7(n=174,61 \%)$. However there are 66 (23\%) band 6 posts. In Scotland, band 6 is the most frequently declared grading - representing $50 \%$ of the declared posts. Just over half ( $n=158,55 \%)$ of the 285 respondents said they had been in post for 10 years or more Figure 2 . 


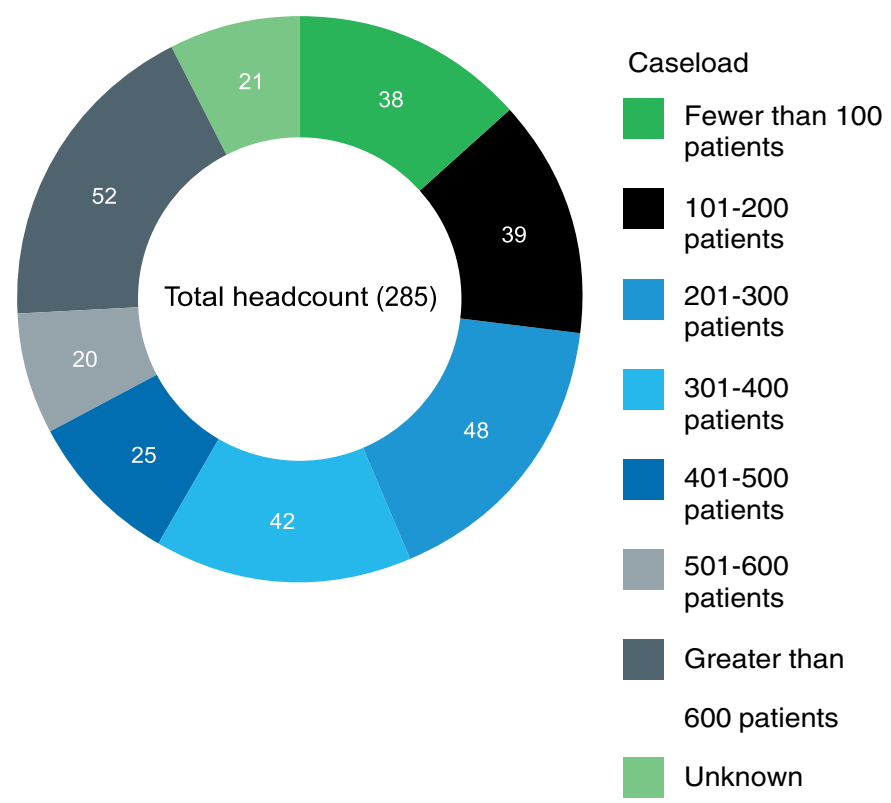

Figure 3 Caseload.

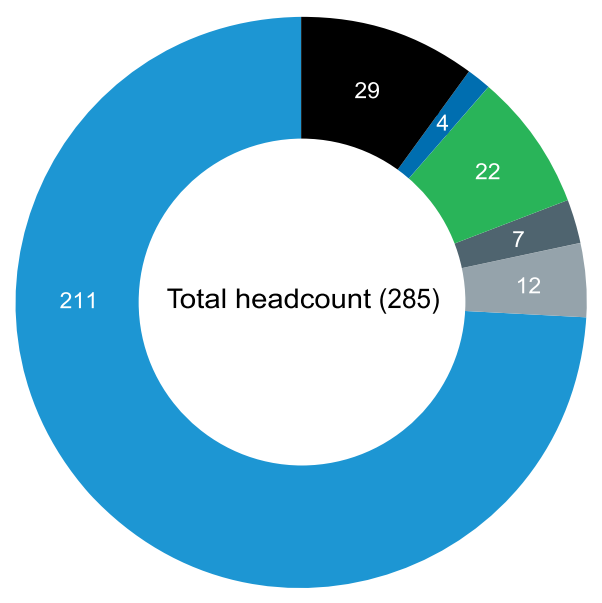

Area of practice

Benign

Chemo/day care

Continence

Research/clinical trials

Surgery (including day surgery)

Uro-oncology (includes prostate, bladder, testicular etc.)

Figure 4 The declared main area of practice.

Only in Scotland were there more than $50 \%$ of nurses who had been in post less than 10 years. Caseloads of 201-300 patients and greater than 600 patients were the most commonly recorded by respondents (Figure 3). In line with the UK specialist cancer nursing census (Macmillan Cancer Support, 2014) the most common job title was CNS with a count of 185 . It is interesting to note the presence of one band 5 and four band 6 nurse practitioners. This role is usually associated with advanced practice roles at band 7 or 8. Respondents were asked to declare their main area of practice - the setting in which they spent over $50 \%$ of their time. A total of 285 responded to this question. The majority worked in a uro-oncology setting (Figure 4) but there is an interesting mix of those working in benign and continence settings. Unlike other cancer sites, which have disease-specific specialist nurses, prostate cancer care is delivered by a range of practitioner groups. Detailed findings are presented below and, where appropriate, set in the content of the national census (Macmillan Cancer Support, 2014).

Time spent working in prostate cancer care Respondents declared a range of years working in prostate cancer care. A total of 158 (55\%) had worked in the field for more than 10 years. Only $32(11 \%)$ had worked in the field for less than 3 years.

The majority of posts were full time ( $n=189,66 \%$ ), however the range of time spent working with prostate cancer patients was variable. Only 23 posts spent 
Table 1 Whole time equivalent (WTE) by geographical distribution

\begin{tabular}{|c|c|c|c|c|c|c|c|}
\hline Network & Benign & $\begin{array}{c}\text { Chemo/day } \\
\text { care }\end{array}$ & Continence & $\begin{array}{c}\text { Research/ } \\
\text { clinical trials }\end{array}$ & $\begin{array}{l}\text { Surgery } \\
\text { (including } \\
\text { day surgery) }\end{array}$ & $\begin{array}{c}\text { Uro-oncology } \\
\text { (including prostate, } \\
\text { bladder, testicular etc.) }\end{array}$ & Total \\
\hline Cheshire and Merseyside & 0.8 & 0.0 & 0.0 & 0.0 & 0.5 & 1.2 & 2.5 \\
\hline East Midlands & 0.0 & 0.3 & 0.0 & 0.0 & 0.8 & 3.0 & 4.0 \\
\hline East of England & 0.2 & 0.0 & 0.2 & 0.6 & 0.0 & $16 \cdot 4$ & $17 \cdot 4$ \\
\hline Greater Manchester, Lancashire and South Cumbria & 0.8 & 0.2 & 0.3 & 0.0 & 0.0 & $13 \cdot 2$ & $14 \cdot 4$ \\
\hline London & 1.4 & 0.0 & 1.2 & 0.0 & 0.0 & $16 \cdot 3$ & 18.9 \\
\hline Northern England & 0.0 & 0.0 & 0.3 & 0.3 & 0.4 & $4 \cdot 0$ & $5 \cdot 0$ \\
\hline South East Coast & 0.5 & 0.7 & 0.0 & 0.0 & 0.0 & 11.6 & $12 \cdot 8$ \\
\hline South West Coast & $1 \cdot 1$ & 0.1 & 0.7 & 0.4 & 1.0 & $13 \cdot 2$ & $16 \cdot 6$ \\
\hline Thames Valley & 0.0 & 0.0 & 0.0 & 0.0 & 0.0 & $2 \cdot 1$ & $2 \cdot 1$ \\
\hline Wessex & 0.7 & 0.0 & 0.8 & 0.0 & 0.5 & $7 \cdot 3$ & $9 \cdot 3$ \\
\hline West Midlands & 0.4 & 0.0 & 0.1 & 0.0 & 0.6 & $7 \cdot 0$ & 8.1 \\
\hline Yorkshire and the Humber & 0.9 & 0.0 & 1.0 & 1.5 & 0.0 & $6 \cdot 7$ & $10 \cdot 0$ \\
\hline North Wales & 0.0 & 0.0 & 0.0 & 0.0 & 0.0 & 1.0 & 1.0 \\
\hline South Wales & 0.0 & 0.0 & 0.1 & 0.5 & 0.1 & $6 \cdot 8$ & 7.6 \\
\hline Northern Ireland & 0.3 & 0.0 & 0.0 & 0.0 & 0.0 & $2 \cdot 0$ & $2 \cdot 3$ \\
\hline NHS Grampian & 0.0 & 0.0 & 0.0 & 0.3 & 0.8 & $2 \cdot 3$ & 3.4 \\
\hline NHS Highland & 0.0 & 0.0 & 0.0 & 0.0 & 0.0 & 0.8 & 0.8 \\
\hline NHS Orkney & 0.0 & 0.0 & 0.0 & 0.0 & 0.0 & 0.0 & 0.0 \\
\hline NHS Shetland & 0.0 & 0.0 & 0.0 & 0.0 & 0.0 & 0.0 & 0.0 \\
\hline NHS Tayside & 0.3 & 0.0 & 0.0 & 0.0 & 0.0 & 0.3 & 0.6 \\
\hline NHS Western Isles & 0.0 & 0.0 & 0.0 & 0.0 & 0.0 & 0.0 & 0.0 \\
\hline NHS Borders & 0.0 & 0.0 & 0.0 & 0.0 & 0.0 & 0.8 & 0.8 \\
\hline NHS Dumfries and Galloway & 0.0 & 0.0 & 0.0 & 0.0 & 0.0 & 0.0 & 0.0 \\
\hline NHS Fife & 0.0 & 0.0 & 0.0 & 0.0 & 0.0 & $2 \cdot 2$ & $2 \cdot 2$ \\
\hline NHS Lothian & 0.0 & 0.0 & 0.1 & 0.0 & 0.0 & 1.0 & $1 \cdot 1$ \\
\hline NHS Ayrshire and Arran & 0.8 & 0.0 & 0.0 & 0.0 & 0.0 & 0.5 & $1 \cdot 3$ \\
\hline NHS Forth Valley & 0.0 & 0.0 & 0.0 & 0.0 & 0.0 & 0.0 & 0.0 \\
\hline NHS Greater Glasgow and Clyde & 0.0 & 0.0 & 0.1 & 0.0 & 0.0 & $1 \cdot 3$ & 1.4 \\
\hline NHS Lanarkshire & 0.0 & 0.0 & 0.0 & 0.0 & 0.0 & 0.5 & 0.5 \\
\hline Total & $8 \cdot 1$ & $1 \cdot 3$ & $5 \cdot 0$ & 3.5 & $4 \cdot 7$ & $121 \cdot 3$ & $144 \cdot 0$ \\
\hline
\end{tabular}

$100 \%$ of their time caring for men with prostate cancer. Thirty-five nurses spent less than $30 \%$ of their time caring for men with prostate cancer, offering some specific services such as continence or erectile dysfunction services, or because no uro-oncology post was available. The free text responses also reflected the challenge of covering multiple services:

I work with benign and cancer patients. Find it difficult to give the cancer patients the time that they may need due to the workload balance. Currently trying to bid for administration hours and more nursing hours for the benign patients.

From these data it is possible to look at a calculated whole time equivalent (WTE) delivering prostate cancer care by geography. This distribution can be seen in Table 1.

\section{Workforce intentions and configuration}

Just under half $(n=140,49 \%)$ of the 285 respondents to this question declared an intention to retire or leave the profession within the next 10 years. Of this group, 58 declared an intention to leave in the next 5 years and 13 within the next year. This will represent a substantial loss of expertise and talent if succession planning is not considered. This finding reflects the English national census which shows an ageing workforce in cancer nursing with $33 \%$ of the specialist nursing workforce now over the age of 50 (Macmillan Cancer Support, 2014). The respondents declared unfilled or frozen posts. This equated to 58.3 full time equivalents (FTE) across the UK. This does not reflect need for posts but only posts currently unfilled. One respondent cited 3.6 WTE posts unfilled. A total of 254 nurses answered a question on the role they had immediately before the specialist role they have now. The largest group (99) 
had a previous role in acute inpatient care. Only 48 had come to a specialist role via a development post, $19 \%$ of those who responded but there also appears to be horizontal (45) and downwards (8) movement. With only three consultant posts in this speciality (Macmillan Cancer Support, 2014), lateral movement is not unsurprising.

The lack of a career structure for uro-oncology roles was a recurrent theme in the qualitative comments. One respondent noted that lack of specialism at ward level means recruitment to specialist uro-oncology posts is 'a major problem ... with no good candidates to take up the role of Urology Nurse Specialist'. There was also a sense of isolation for nurses who were working as the single-handed CNS for urology in a trust.

Workforce reconfiguration was clearly underway in some trusts with some respondents on a fixed-term contract, a secondment or a post funded by charity income with no sense of longevity for the role. Some identified that this was part of a wider review of CNS posts, with one respondent stating that:

For the second time in four years, we have been told posts will be lost or downgraded.

The shift towards more community-focused care provision was seen as a threat to hospital-based posts, rather than as an opportunity for the post-holder to take on more community specialist care provision. The move towards more integrated primary and secondary care trusts in some parts of the UK may be more encouraging for services such as uro-oncology.

The sense of threat to the role in some trusts was also evident. One respondent spoke of the need to ensure I have evidence to demonstrate the benefits of our role and grading. Several respondents identified areas of the service they would like to develop such as 'services for African Caribbean men with prostate cancer, or better transition from hospital to home for men with prostate cancer, but developing these ideas or applying for additional funding was not seen as feasible with the current workload.

\section{Caseload and workload}

There was a wide variation in the declared caseloads. Of 285 responses, 38 nurses (13\%) declared a caseload of less than 100 whilst 52 (18\%) had a caseload of greater than 600 . The most common response was those with a caseload of 600 plus. It is unlikely that a caseload of this size would allow for proactive case management. Workload carried by the individual uro-oncology nurses was variable, particularly in terms of the range of patient problems/ diagnoses covered. Anecdotally mergers within the
NHS had presented specialists with the challenge of multisite cover respondents were asked how many hospital sites they covered. A total of 281 nurses responded to this question. Most nurses (156) cover one hospital site; however, eight cover more than five hospital sites.

The free text responses also indicated that mergers in response to financial pressures presented challenges to multi-site working:

Between a team of three uro-oncology CNSs who cover all five urological cancer sites we cross cover each other when a CNS is on leave which includes cross covering all CNS nurse-led clinics. Our nurse-led clinics are rarely cancelled. (CNS, band 7).

\section{Work left undone}

Over half of the respondents $(n=163,57 \%)$ declared that they were unable to provide best practice nursing interventions (less than $30 \%$ of the time) for patients at one or more points in the cancer journey.

The most frequent interventions not performed were formal Holistic Needs Assessments (HNA), prescribing or recommending medication, and meeting information needs. Both meeting information needs and assessing needs from a holistic perspective form part of national cancer policy in England (Department of Health, 2011), and are also considered best practice in cancer care across the rest of the UK.

Qualitative data showed that workload was deemed to have an impact on patient care, in particular capacity to undertake formal HNA:

Holistic Needs Assessments are offered and patients have to ring/see us for them to be done. No capacity for us to initiate contact. (CNS, band 6)

Capacity means I do not have opportunity/time to complete HNA. (CNS, band 7)

HNA not done formally; assessment of needs done routinely. (CNS, band $8 b$ )

\section{The burden of administration}

The data shows that about $68 \%$ of the respondents who have more than $20 \mathrm{~h}$ of administrative support per week work the lowest amount of overtime (sum $28 / 11+8=68 \%$ ). About $65 \%$ of respondents said they had no administrative support per week or support for clinic letters only. Of these responses, about $86 \%$ declared that they work overtime with about $36 \%$ 


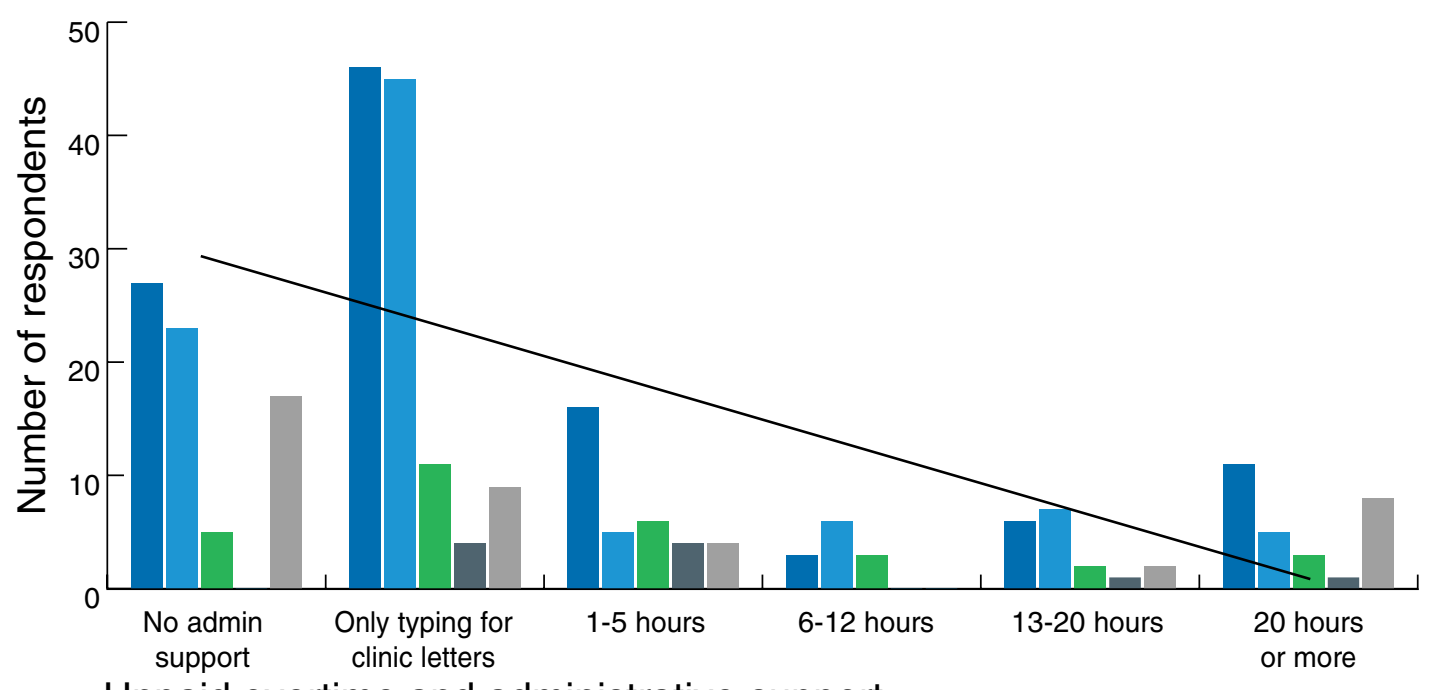

Unpaid overtime and administrative support

Unpaid overtime (weekly average)

1-3 hours 4-7 hours 7-10 hours More than 10 hours None

Figure 5 Unpaid overtime and access to administrative support.

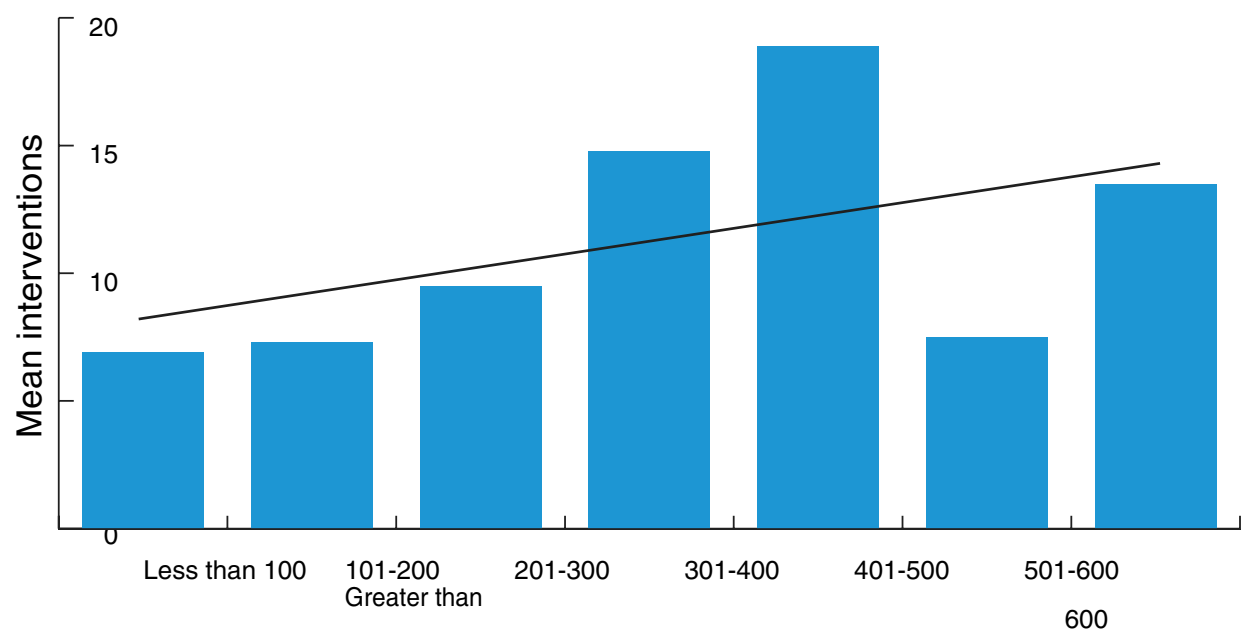

Patient caseload

Figure 6 Mean interventions left undone per whole time equivalent (WTE).

declaring that they work at least $4 \mathrm{~h}$ overtime per week. Having administrative support is associated with lower rates of unpaid overtime (Figure 5). Higher caseloads were associated with a higher mean declared with necessary interventions left undone (Figure 6).

\section{Education and development}

The current workforce is highly educated with many nurses holding post-registration qualifications, the highest level of qualification the nurses declared. A small number of respondents $(n=14,4.9 \%)$ did not answer this question. Thirty-four respondents said they have a masters qualification in nursing, the level recommended in most of the advanced practice frameworks as the standard of education required to fulfil a specialist role.

There was a desire for further education and development activities across the population with 729 items chosen by respondents. The highest demand (179) was for specialist update study days, clinical skills study days (93), advanced practice courses (81) and clinical short courses. Qualitative data indicated that a number of nurses use their own resources (time and money) for Continuing Professional Development 
(CPD), whilst others rely on charity funding (examples given: Macmillan Cancer Support and Prostate Cancer UK). For some nurses, lack of local CPD means that personal development has to be undertaken online.

All education is in my own time. (CNS, band 7)

Workload precludes taking much time off for study. (CNS, band 8a)

Current degree education is self-funded in own time. (CNS, band 7)

\section{CONCLUSIONS OR POSITION STATEMENT, IMPLICATIONS FOR PRACTICE}

The workforce in this specialism is providing complex care but has appeared to evolve without strategic intent and consequently there is a duality to the role for many-caring for patients with a range of diseases.

As prostate cancer is predicted to become the most common cancer overall by 2030 , consideration of strategic planning should be given to patterns of care delivery and the future workforce. Capacity to provide cancer nursing care needs to be addressed nationally and locally.

Despite the known benefits of access to a specialist nurse, the distribution of specialist nurses and incidence-to-nurse ratios vary enormously indicating that there is likely to be inequity of access. In addition, uro-oncology nurses have the highest mean new patient/incidence (159 per WTE) and 2 year prevalence (247 per WTE) of specialist nurses in England (Macmillan Cancer Support, 2014). This work indicates that unlike other cancers, prostate cancer nursing care is rarely provided by a prostate CNS. This is corroborated by the national cancer nursing census which shows that only $2 \%$ of the specialist nursing workforce in
England is prostate specific - approximately the same number as a rare cancer such as sarcoma (Macmillan Cancer Support, 2014).

From a workforce perspective, retention of staff in specialist areas is a key concern. Autonomy and empowerment have been identified as key 'magnet factors' in attracting and keeping high quality staff (Armstrong and Laschinger, 2006). The examples of CNS activity provided above indicate that nurse specialists in some areas are able to exercise these attributes; however, there appears to be a deficit of talent management or provision for succession planning making this a workforce in decline.

\section{ACKNOWLEDGEMENTS}

This work was funded by Prostate Cancer UK (reg. charity) and carried out by an independent research team from Plymouth University, London South Bank University and Mouchel Management Consulting Limited. We thank the President, committee and members of the British Association of Urological Nurses. Steve Candler, Senior Network and Domain Manager, Thames Valley Strategic Clinical Networks, NHS England. Doreen Smulders and Dale Rominger, Prostate Cancer UK volunteers. We thank Jaqueline Goodchild and Sophie Townsend, Macmillan Cancer Support; the NHS/NHIR Contact, Help, Advice and Information Network (CHAIN). We also thank the President and members of the United Kingdom Oncology Nursing Society. Frances Pickersgill and Janet Snell, Nursing Standard.

\section{AUTHOR CONTRIBUTIONS}

Data collection was done by A.L., J.B., L.F., M. M., analysis done by A.L., A.S., F.H., R. E., A. O., P.T., manuscript preparation by all the authors.

\section{WHAT IS KNOWN ABOUTTHIS TOPIC}

- Prostate cancer is the most common cancer in men in the UK accounting for $25 \%$ of all new cases of cancer. It is predicted to become the most common cancer overall by 2030.

- The value of specialist nurses in cancer is well documented but there was not detailed intelligence on this workforce.

\section{WHAT THIS PAPER ADDS}

- This paper is the result of a national survey. The work of specialist nurses caring for men with prostate cancer is clinically complex and appears to cover most key times in the cancer journey. However, workload appears to be limiting the care that the nurses are able to provide with over half the respondents (163) saying that they left work undone for patients.

- The workforce appears to ageing and in decline with limited opportunities for succession planning and career progression. This should be addressed in light of the predicted rise in men with prostate cancer. 


\section{REFERENCES}

Armstrong KJ, Laschinger H. (2006). Structural empowerment, magnet hospital characteristics and patient safety culture. Journal of Nursing Care Quality; 21 (2): 124-132.

Cancer Research UK. (2014a). Prostate cancer incidence statistics: trends over time, 1975-2011. http://www.cancerresearchuk. org/cancer-info/cancerstats/types/prostate/incidence/ \#trends (accessed 01/10/14).

Cancer Research UK. (2014b). Prostate cancer incidence statistics: by age (2009-2011). http://www.cancerresearchuk.org/ cancer-info/cancerstats/types/prostate/incidence/\#age (accessed 01/10/14).

Cancer Research UK. (2014c). Prostate cancer mortality statistics: by country in the UK (2012). http://www.cancer researchuk.org/cancer-info/cancerstats/types/prostate/ mortality/\#age (accessed 01/10/14).

Department of Health. (1995). A Policy Framework for the Commissioning of Cancer Services: A Report by the Expert Advisor Group on Cancer to the Chief Medical Officers of England and Wales. Department of Health. London: HMSO.

Department of Health. (1999). Making a Difference: Strengthening the Nursing, Midwifery and Health Visiting Contribution to Health and Healthcare. Department of Health. London: HMSO.

Department of Health. (2000). A Health Service for all the Talents: Developing the NHS Workforce. Consultation Document on the Review of Workforce Planning. Department of Health. London: HMSO.

Department of Health. (2007). The cancer reform strategy. http://webarchive.nationalarchives.gov.uk/+/www.dh.gov. uk/en/Healthcare/Cancer/DH_091120 (accessed 10/10/14).

Department of Health. (2010). National Cancer Patient Experience Survey Programme - 2010: National Survey report. http://tinyurl.com/3x8x8mz (accessed 09/10/14).

Department of Health. (2011). Improving outcomes: a strategy for cancer. https://www.gov.uk/government/uploads/system/ uploads/attachment_data/file/213785/dh_123394.pdf (accessed 23/10/14).

Department of Health. (2012). National Cancer Patient Experience Survey 2011/2012 - National Report. http://tinyurl.com/ crpdaxx (accessed 23/10/14).

Farrell C, Molassiotis A, Beaver K, Heaven C. (2011). Exploring the scope of oncology specialist nurses' practice in the UK. European Journal of Oncology Nursing; 15: 160-166.

Lowe G, Plummer V, O'Brien AP, Boyd L. (2012). Time to clarify - the value of advanced practice nursing roles in health care. Journal of Advanced Nursing; 68 (3): 677-85.

Macmillan Cancer Support. (2014). Census of the specialist cancer nursing workforce (England). http://www.macmillan.
org.uk/Documents/AboutUs/Research/Researchand evaluationreports/Macmillan-Census-Report-England.pdf (accessed 01/07/2015).

Maddams J, Utley M, Møller H. (2014). Projections of cancer prevalence in the United Kingdom, 2010-2040. British Journal of Cancer; 107 (7): 1195-202.

Mistry M, Parkin DM, Ahmad AS, Sasieni P. (2011). Cancer incidence in the United Kingdom: projections to the year 2030. British Journal of Cancer; 105 (11): 1795-803.

National Cancer Action Team. (2010). Excellence in cancer care: the contribution of the clinical nurse specialist. http://webarchive.nationalarchives.govuk/20130513211 237/; http://www.ncat.nhs.uk/sites/default/files/workdocs/Excellence\%20in\%20Cancer\%20Care.pdf (accessed $21 / 10 / 14)$.

National Cancer Action Team. (2011). Quality in Nursing Clinical Nurse Specialists in Cancer Care; Provision, Proportion and Performance. A census of the cancer specialist nurse workforce in England. http://webarchive.national archives.gov.uk/20130513211237/http://ncat.nhs.uk/sites/ default/files/NCAT $\% 20$ Census $\% 20$ of $\% 20$ the $\% 20 \quad$ Cancer\%20Specialist $\% 20$ Nurse $\% 20$ Workforce $\% 202011$.pdf (accessed 21/10/15).

National Institute for Health and Clinical Excellence. (2014). Prostate cancer: diagnosis and treatment [CG175]. http:// tinyurl.com/39tna9r (accessed 09/10/14).

NHS England. (2013). Cancer Patient Experience Survey 2012-2013 National Report. http://tinyurl.com/ntxeh52 (accessed 23/10/14).

NHS England. (2014). Cancer Patient Experience Survey 2014 National Report. http://tinyurl.com/oz96j68 (accessed 23/10/14).

Prostate Cancer UK. (2013). The views of prostate cancer patients in Scotland (accessed 01/07/2015).

Ream E, Wilson-Barnett J, Faithfull S, Fincham L, Khoo V, Richardson A. (2009). Working patterns and perceived contribution of prostate cancer clinical nurse specialists: a mixed method investigation. International Journal of Nursing Studies; 46: $1345-1354$.

Richards M. (2010). National Cancer Patients' Experience Survey Programme 2010. http:/ / tinyurl.com/68spyhm (accessed 09/10/14).

Trevatt P, Leary A. (2010). A census of the advanced and specialist cancer nursing workforce in England, Northern Ireland and Wales. European Journal of Oncology Nursing; 14 (1): 68-73.

Welsh Government. (2014). Wales Cancer Patient Experience Survey: National Report. http://tinyurl.com/lvklbd5 (accessed $23 / 10 / 14)$. 